\title{
Isolated bone erosions likely not clinically significant
}

\author{
Bruce Rothschild ${ }^{1,2 *}$ and Lyman Jellema ${ }^{3}$ \\ ${ }^{1}$ Arthritis Center, 5010 N Weir, Muncie, IN 47304, USA \\ ${ }^{2}$ Carnegie Museum, 4400 Forbes Ave, Pittsburgh, PA 15213, USA \\ ${ }^{3}$ Cleveland Museum of Natural History, 1 Wade Oval Dr, Cleveland, OH 44106, USA
}

\begin{abstract}
Background: Synovial joint erosions are generally considered the result of an inflammatory process, permitting identification of the underlying form of arthritis. However, they are sometimes perceived in isolation, in the absence of any disorder known to produce erosions. In addition to the character of the erosions, a tool helpful in characterizing known forms of inflammatory arthritis is their gender and age distribution as a population phenomenon.

Methods: Hands and feet of individuals in the Hamann-Todd human skeletal collection were macroscopically examined to identify individuals with isolated (single or two) appendicular articular or peri-articular cortical disruptions in absence of axial skeletal erosions, fusion, syndesmophytes or calcium pyrophosphate deposition disease-related calcific deposits. Gender and age were additionally recorded for individuals identified with rheumatoid arthritis, spondyloarthropathy and calcium pyrophosphate deposition disease.
\end{abstract}

Results: Isolated articular and periarticular cortical disruption was recognized in 61 (4 women, 57 men) among 1620 individuals, independent of race.

Discussion: Epidemiologic analysis revealed a pattern of isolated erosions that could not be attributed to the diseases that today are recognized to commonly cause bone erosion. If not associated with other skeletal manifestations of inflammatory/crystalline arthritis or clinical evidence of synovitis, they likely are not clinically significant.

\section{Introduction}

One of the arbitrators of aggressive rheumtologic intervention is presence of erosins, but are all erosions pertinent? Microscopic bone alterations (in the form of erosions) caused by rheumatoid arthritis, spondyloarthropathy, calcium pyrophosphate deposition disease and gout have recently been reviewed, identifying variables allowing distinguishing among them [1]. Unfortunately, those definitive alterations are difficult to recognize at lesser degrees of magnification. While bone alterations related to known rheumatologic diseases are highly characteristic, even when present as isolated erosions, the details permitting recognition of the specific underlying disorder are below the resolution of standard radiologic techniques available to clinical practitioners. High magnified views (100-200 fold) are required. This is especially problematic when only isolated erosions are discovered. Are these forme fruste of known diseases and therefore prognostic or simply residue of some entity as yet not recognized/identified, which subsequently resolved.

Synovial joint erosions are generally considered the result of an inflammatory process, permitting identification of the underlying form of arthritis, and as an indication for aggressive therapeutic intervention [2]. However, they are sometimes perceived (radiologically, on the basis of articular and periarticular cortical discontinuities) in isolation, in the absence of any other indication of an inflammatory process [3-5].

Most isolated erosions perceived radiologically in otherwise healthy individuals are identified as optical/radiologic illusions, related to the irregular shape of joints or their margins or to ligament attachments and overlapping shadows [6,7]. However, real erosions do occur in individuals without any disorder known to produce erosions [8]. What is their significance? Are they harbingers of future disease or simply residua of isolated events of as yet unidentified derivation? Examination of defleshed skeletons obviates the problem of optical illusion/overlapping shadows and permits clearly delineating cortical defects unrelated to tendon or ligament attachments $[9,10]$.

The source of these isolated erosions has been a matter for speculation. Are they forme-fruste of a known inflammatory or crystalline arthritis? This is a question that has proven inaccessible to assess without full clinical information. (Note that most skeletal collections, even those with cause of death and autopsy information, lack clinical history and autopsies seldom comments on presence or absence of joint disease). Another approach is required.

In addition to the character of the erosions, a tool that has been helpful in characterizing known forms of inflammatory arthritis in skeletal collections/archeologic sites is their distribution (epidemiologic) in the population [9-17]. What is the gender distribution? How prevalent is it in each decade of life? One of the challenges of epidemiologic studies in archeologic samples is lack of adequate criteria for distinguishing specific ages of older individuals and their variable survival. This could compromise analysis, unless one limits comparison to similar age cohorts and also limits diagnostic considerations to those diseases which manifest in or by those decades. A skeletal collection composed

${ }^{\star}$ Correspondence to: Bruce Rothschild, Carnegie Museum, 4400 Forbes Ave, Pittsburgh, PA 15213, USA, Tel: 785-615-1523; E-mail: spondylair@gmail.com

Key words: calcium pyrophosphate deposition disease, erosion, gout, rheumatoid arthritis, spondyloarthritis

Received: December 05, 2019; Accepted: December 13, 2019; Published: December 17, 2019 
of individuals of known age at death and which has been documented as representative of the population from which it was drawn, the Haman-Todd human skeletal collection, provides the opportunity for such an analysis $[9,10,14,17,18]$. Thus, the age and gender profile of the various forms of inflammatory/crystalline arthritis that have significant population penetrance (as identified in that sample) can be compared and contrasted with that of isolated erosions.

\section{Methods}

Hands and feet of individuals in the Hamann-Todd human skeletal collection were macroscopically examined to identify individuals with isolated (single or two) appendicular articular or peri-articular cortical disruptions $[8,19]$. Individuals with axial skeletal erosions, fusion or syndesmophytes, calcium pyrophosphate deposition disease-related calcific deposits, hypertrophic osteoarthropathy or clinical diagnoses of renal disease, syphilis, cancer and gout were specifically excluded. Individuals with projecting peri-articular enthesial or Sharpey fibers (identifying ligamentous insertion-related defects) were excluded, as were individuals with articular crumbing (indicative of calcium pyrophosphate deposition disease) rather than sharply defined erosions or indentations related to "pressure erosions" [17,20,21-23]. Individuals with renal, infectious disease (e.g., syphilis) or cancer were also excluded because of their cortical bone expression in these diseases $[13,14,17,22,24-29]$.

Gender and age were recorded for individuals identified with rheumatoid arthritis, spondyloarthropathy and calcium pyrophosphate deposition disease. Identification of rheumatoid arthritis was predicated on sharply defined cortical defects (erosions and their skeletal distribution) in the absence of remodeling $[22,10]$. Spondyloarthropathy was recognized by presence of well-defined, but remodeled erosions associated with reactive new bone formation $[22,14]$. Identification of calcium pyrophosphate deposition disease was predicated on the crumbling character of its erosions and articular surface calcifications [17]. Gout was recognized by the sharp definition of its erosions, surrounded by dense new reactive bone and presence of discrete birefringent material at its base [25]. Bone indentations permitted identification of pressure erosions. The significance of age distribution of isolated and disease-related erosions was assessed by Chi square and Fisher exact tests [23].

\section{Results}

Isolated articular and periarticular cortical disruption was recognized in 61 of 1620 individuals (Table 1). Examination of the epidemiology of isolated erosions revealed a pattern quite different from that of disorders known to cause joint erosions as a population phenomenon, both in gender and age predisposition. Isolated erosions were observed in 4 women, 57 men. They were equally represented in African American and Caucasian women. They were observed in 21 of 348 African American males and 36 of 648 Caucasian males examined in the Hamann-Todd collection. Prevalence was independent of race. The most disparate prevalence (according to race) was in the $8^{\text {th }}$ decade, but was not statistically significant (Fisher exact test $=0.0677$ ).

\section{Discussion}

Isolated erosions were predominantly a male phenomenon, independent of race (Table 1). Examination of the raw data in Table 1 reveals differences between the epidemiology of isolated erosions and that of known causes of inflammatory arthritis in the HamannTodd human skeletal collection but requires additional calculations to convert gender-based prevalence to be applicable to the general population. Such epidemiological comparison requires correcting the Hamann-Todd human skeletal collection male accession bias. Gender ratios in the Hamann-Todd human skeletal collection are unbalanced, heavily in favor of males. To relate skeletal collection findings to the general population, the gender prevalence of isolated erosions and of diseases must be adjusted accordingly. Epidemiologic analysis based on that calculation (Table 2) revealed a pattern of isolated erosions that could not be attributed to the diseases that today are recognized to commonly cause bone erosion. Isolated erosions were more prevalent in the fourth and fifth decades of life, less in the $6^{\text {th }}$ and $7^{\text {th }}$ and again

Table 1. Gender and age prevalence of isolated erosions contrasted with identified individuals with rheumatoid arthritis, spondyloarthropathy, calcium pyrophosphate deposition disease

\begin{tabular}{|c|c|c|c|c|c|}
\hline Disease & Isolated & Rheumatoid & Spondyloarthropathy & CPPD & Denominator \\
\hline Gender (M/F) & $57 / 4$ & $34 / 13$ & $72 / 6$ & $164 / 39$ & $1345 / 275$ (total) \\
\hline Decade & & & & & (by decade) \\
\hline $3^{\text {rd }}$ & 1 & 1 & 1 & 1 & 100 \\
\hline $4^{\text {th }}$ & 3 & 8 & 9 & 6 & 265 \\
\hline $5^{\text {th }}$ & 9 & 5 & 19 & 30 & 412 \\
\hline $6^{\text {th }}$ & 8 & 18 & 13 & 43 & 350 \\
\hline $7^{\text {th }}$ & 5 & 9 & 15 & 45 & 279 \\
\hline $8^{\text {th }}$ & 6 & 2 & 17 & 45 & 131 \\
\hline$>8^{\text {th }}$ & 2 & 1 & 2 & 12 & 83 \\
\hline
\end{tabular}

Table 2. Gender and age prevalence of isolated erosions and known erosive diseases, corrected for gender discrepancy and age representation in the Hamann-Todd human collection.

\begin{tabular}{|c|c|c|c|c|c|}
\hline Disease & Isolated & Rheumatoid & Spondyloarthropathy & CPPD & Gout§ \\
\hline Gender specificity $(\mathrm{M} / \mathrm{F})^{*}$ & $4.2-1.4$ & $0.1: 2.2$ & $2.4: 1$ & $5.5-6.5$ & $3: 1$ \\
\hline \multicolumn{6}{|l|}{ Decade } \\
\hline $3^{\text {rd }}$ & 1. & 1 & 1 & 1 & $<1$ \\
\hline $4^{\text {th }}$ & 5.2 & 3.0 & 3.4 & 2.3 & $<1$ \\
\hline $5^{\text {th }}$ & 2.2 & 1.2 & 4.6 & 7.3 & 2 \\
\hline $6^{\text {th }}$ & 2.3 . & 5.1 & 3.7 & 12.3 & 3 \\
\hline $7^{\text {th }}$ & 1.8 & 3.2 & 5.4 & 16.1 & 4 \\
\hline $8^{\text {th }}$ & 4.6 & 1.5 & 13.0 & 34.3 & 5 \\
\hline$>8^{\text {th }}$ & 2.5 & 1.2 & 2.4 & 14.4 & 4 \\
\hline
\end{tabular}

* Prevalence corrected for Hamann-Todd gender disparity $(83 \%$ male $)$

$\S$ Derived from Mikuls, et al. [30] 
more common after the $7^{\text {th }}$ than rheumatoid arthritis. They were less prevalent in the $5^{\text {th }}-8^{\text {th }}$ decades than spondyloarthritis. They were more prevalent in the $4^{\text {th }}$ and less after the $2^{\text {nd }}$ decade than CPPD. Thus, isolated erosions present a unique pattern, different than that noted with those disorders. They apparently derive from a source other than those of currently recognized forms of inflammatory arthritis. Could those isolated erosions recognized in the Hamann-Todd collection be related to a specific problem in the late $19^{\text {th }} /$ early $20^{\text {th }}$ century that has subsequently resolved?

Radiologic demonstration of erosions is one of the indicators for aggressive therapeutic intervention, at least in the presence of active synovitis. That is the caveat: If synovitis is not present, they may simply represent the residua of burnt out disease, and not an indicator for aggressive anti-inflammatory agent initiation. Perhaps isolated erosions could be similarly considered? Similarly, the significance of isolated erosions in the absence of known underlying disease must be considered. One approach is to first assess if damage characteristically identifying a disorder, such as evidence of active synovitis is present. If none is found, what would be clinically appropriate?

Isolated erosions are just that. If not associated with other skeletal manifestations of inflammatory/crystalline arthritis or clinical evidence of synovitis, they likely are not clinically significant. Future study is indicated to evaluate and follow individuals with radiologic evidence of erosions to assess current, past and future incidence of synovitis or other diseases to which they might hypothetically be related. The key to assessing the significance of isolated erosions is a careful examination for evidence of synovitis.

\section{Authorship}

Both authors (BMR and LJ) contributed equally.

\section{Funding}

There is no external Funding

\section{Conflicts of interest}

None.

\section{References}

1. Rothschild BM (2018) Differential diagnostic perspectives provided by en face microscopic examination of articular surface defects. Clin Rheumatol 31: 831-836. [Crossref]

2. Schett G, Graveallese G, Ravallese E (2012) Bone erosion in rheumatoid arthritis: Mechanisms, diagnosis and treatment. Nat Rev Rheumatol 8: 656-664. [Crossref]

3. Mangnus I, Van Steebergen HW, Reijnierse M, van der Helm AH (2016) Magnetic resonance imaging-detected features of inflammation and erosions in symptom-free persons from the general population. Arthritis Rheumatol 68: 2593-2602. [Crossref]

4. Mistlin A (2004) Joint examination skills: are rheumatology specialist registrars adequately trained? Rheumatology (Oxford) 43: 387. [Crossref]

5. Scharmga A, Peters M, Van Tubergen A, van den Bergh J, Barnabe C, et al. (2016) Heterogeneity of cortical breaks in hands of patients with rheumatoid arthritis and healthy controls imaged by high-resolution peripheral quantitative computed tomography. J Rheumatol 43: 1914-1920. [Crossref]

6. Barrett JF, Keat N (2004) Artifacts in CT: recognition and avoidance. Radiographics 24: 1679-1691. [Crossref]

7. Rothschild BM (2010) Significance of "Erosion-like Lesions" in "Healthy Controls". $J$ Rheumatol 37: 1964. [Crossref]

8. Rothschild BM (2017a) Nature of perceived bone defects in apparently otherwise healthy individuals: Source of the erosive perspective. J Clin Rheumatol 24: 437-439. [Crossref]

9. Rothschild BM (1995) Paleopathology, its character and contribution to understanding and distinguishing among rheumatologic diseases: Perspectives on rheumatoid arthritis and spondyloarthropathy. Clin Exp Rheumatol 13: 657-662. [Crossref]
10. Rothschild BM, Woods RJ (1990) Symmetrical erosive disease in Archaic Indians: The origin of rheumatoid arthritis in the New World. Semin Arthritis Rheum 19: 278-284. [Crossref]

11. Dutour O, Panuel M, Rothschild BM (1994) Spondyloarthropathies in early Holocene Saharan population. Journal of Comparative Human Biology 45: 44.

12. Rothschild BM, Rothschild C (1993) Nineteenth century spondyloarthropathy independent of socioeconomic status: Lack of skeletal collection bias. J Rheumatol 20: 314-319. [Crossref]

13. Rothschild BM, Woods RJ, Ortel W (1990) Rheumatoid arthritis "In the buff": Erosive arthritis in representative defleshed bones. American Journal of Physical Anthropology 82: 441-449.

14. Rothschild BM, Woods RJ (1991) Spondyloarthropathy: Erosive arthritis in representative defleshed bones. Am J Phys Anthropol 85: 125-134. [Crossref]

15. Rothschild BM, Woods RJ (1993) Geographic distribution of calcium pyrophosphate deposition disease (CPPD) in pre-Columbian North America: Independent validation of diagnostic criteria. Clin Exp Rheumatol 11: 315-318. [Crossref]

16. Rothschild BM, Woods RJ, Rothschild C, Sebes JI (1992a) Geographic distribution of rheumatoid arthritis in ancient North America: Implications for pathogenesis. Semin Arthritis Rheum 22: 181-187. [Crossref]

17. Rothschild BM, Woods RJ, Rothschild C (1992b) Calcium pyrophosphate deposition disease: Description in defleshed skeletons. Clin Exp Rheumatol 10: 557-564. [Crossref]

18. Rothschild BM, Rothschild C (1998) Recognition of hypertrophic osteoarthropathy in skeletal remains. J Rheumatol 25: 2221-2227. [Crossref]

19. Mensforth RP, Latimer BM (1989) Hamann-Todd collection aging studies: Osteoporosis fracture syndrome. Am J Phys Anthropol 80: 461-479. [Crossref]

20. Shaibani A, Workman R, Rothschild B (1993) The significance of enthesitis as a skeletal phenomenon. Clin Exp Rheumatol 11: 399-403. [Crossref]

21. Rothschild BM (2013) Nondestructive, epi-illumination surface microscopic characterization of surface discontinuity in bone: a new approach offers a descriptive vocabulary and new insights. Anat Rec (Hoboken) 296: 580-589. [Crossref]

22. Resnick D (2002) Diagnosis of Bone and Joint Disorders, 4th edition, Philadelphia, Saunders, 3870-3897.

23. Rothschild BM, Martin LD (2006) Skeletal Impact of Disease. Albuquerque: New Mexico Museum of Natural History Press.

24. Hershkovitz IH, Rothschild BM, Dutour O, Greenwald C (1998) Clues to recognition of fungal origin of lytic skeletal lesions. Am J Phys Anthropol 106: 47-60. [Crossref]

25. Rothschild BM, Heathcote GM (1995) Characterization of gout in a skeletal population sample: Presumptive diagnosis in Micronesian population. Am J Phys Anthropol 98: 519-525. [Crossref]

26. Rothschild BM, Rothschild C (1995a) Treponemal disease revisited: Skeletal discriminators for Yaws, Bejel, and venereal syphilis. Clin Infect Dis 20: 1402-1408. [Crossref]

27. Rothschild BM, Rothschild C (1995b) Comparison of radiologic and gross examination for detection of cancer in defleshed skeletons. Am J Phys Anthropol 96: 357-363. [Crossref]

28. Rothschild C, Rothschild B, Hershkovitz I (2002) Clues to recognition of kidney disease in archeologic record: Characteristics and occurrence of leontiasis ossea Rheumatismo 54: 133-143. [Crossref]

29. Winland K, Rothschild BM, Rothschild C (1997) Reproducibility of patterns of tuberculosis-related periosteal reaction in the Hamman-Todd, Grant \& Terry Collections. Am J Phys Anthropol 24: 243.

30. Mikuls TR, Farrar JT, Bilker WB, Fernandes S, Schumacher HR Jr, et al. (2005) Gout epidemiology: Results from the UK General Practice Research Database, 1990-1999. Annals of Rheumic Diseases 64: 267-272. [Crossref]

Copyright: (C2019 Rothschild B. This is an open-access article distributed under the terms of the Creative Commons Attribution License, which permits unrestricted use, distribution, and reproduction in any medium, provided the original author and source are credited. 